\title{
Métodos de Sistemas de Proteção por extintores
}

Kaio Vinicius Resende Carvalho ${ }^{1}$; Bruno Lopes Falcão ${ }^{2}$

\begin{abstract}
Resumo: As escolas padrões 'H' do estado do Ceará foram construídas no governo de Virgílio Távora na e década de 70. Naquela época, não existia a preocupação de fazer uma escola de modo a garantir a segurança de alunos e funcionário na hora de um sinistro. Hoje, existem várias Normas Técnicas que podem ser usadas na prevenção de incêndios em escolas, uma delas é a NR 23 (Proteção Contra Incêndios) onde recomenda-se que todas as empresas devem possuir proteção contra incêndio e saídas suficientes para a rápida retirada do pessoal em serviço. Além da NR 23, outra norma que aborda o dimensionamento de aparelhos extintores é a norma técnica do Corpo de Bombeiros do Ceará $\mathrm{N}^{\circ}$ 004/2008 (sistema de proteção por aparelhos extintores) que estabelece critérios para proteção contra incêndio em edificações e áreas de riscos. Esse trabalho visa o dimensionamento de uma escola padrão " $\mathrm{H}$ " do Estado do Ceará utilizando apenas aparelhos extintores, ressaltando que em uma escola não pode possuir apenas um método de prevenção e combate ao incêndio ela deve seguir todas as normas do corpo de bombeiros de seu estado. A escola em estudo possui uma área total de $2.790 \mathrm{~m}^{2}$ e sua área construída é de $1.150,00 \mathrm{~m}^{2}$.
\end{abstract}

Palavras-Chave: Segurança do Trabalho; Princípio de incêndio; Extintores

\section{Protection Systems Methods for Fire Extinguishers}

\begin{abstract}
Schools standards 'H' of the Ceará state were built in the government of Virgilio Tavora in the 70s and that time there was no concern to a school to ensure the safety of students and staff at the time of an accident. Today, there are various technical standards that can be used in fire prevention in schools one of them is NR 23 Fire Protection, which recommends that all companies must have fire protection, sufficient outlets for the rapid withdrawal of staff serving in case of fire, enough equipment to fight the fire at its inception, people with training in proper use of this equipment and other specifications contained in this regulatory standard. In addition to the NR 23, another item that deals with fire extinguishers lying at the entrance of the body of the State of Ceará firefighters who is the Technical Norm No. 004/2008 (protection system for fire-extinguishers) establishing criteria for protection Fire in buildings and areas of risk through fire extinguishers devices. Thus, this work aims at the design of a standard school "H" of Ceará using only fire extinguishers, noting that a school can not have just one method of prevention and fire fighting she must follow all body standards Fire your state. The school under study has a total area of 2,790 square meters and its building area is $1,150.00 \mathrm{~m}^{2}$.
\end{abstract}

Keywords: Workplace safety; Fire principle; extinguishers.

\footnotetext{
${ }^{1}$ Graduado em engenharia civil pela Universidade Estadual Vale do Acaraú-UEVA. E-mail: kaiovinicius.civil@ gmail.com;

${ }^{2}$ Universidade Estadual Vale do Acaraú-UEVA. E-mail: brunolf@yahoo.com.br
} 


\section{Introdução}

Os maiores riscos de incêndio em escolas são determinados por aquilo que chamamos de carga de incêndio nos compartimentos do prédio, principalmente, em locais onde ficam armazenados materiais de fácil combustão, como: papéis, plásticos e líquidos inflamáveis.

Nos últimos anos, assistiu-se através da mídia uma série de incêndios acontecendo em várias escolas pelo país, incêndios esses, que podem ser combatidos facilmente através da instalação de aparelhos extintores nos diversos ambientes escolares, visando uma maior segurança para as pessoas ali presentes.

Extintores são aparelhos de fácil manuseio e excelente eficácia no combate ao princípio de incêndio, pois conseguem proporcionar uma sensação de maior segurança para as pessoas que trabalham ou transitam nos diversos locais sujeitos a incêndio. Porém, não se pode esquecer que, além da instalação desses aparelhos é necessário, ainda, o treinamento do pessoal para o manuseio adequado desses equipamentos.

Desde a construção das escolas padrões "H" no Estado do Ceará, nunca se pensou ou foi implementado um sistema de combate a incêndio nesse modelo de escola. Um princípio de incêndio em uma escola desse modelo poderá tomar uma magnitude muito grande, podendo acarretar em danos materiais consideráveis, passando pela perda completa da edificação e chegando até a morte de indivíduos presentes no local.

O presente trabalho tem como objetivo demonstrar o dimensionamento de aparelhos extintores para as escolas padrão " $\mathrm{H}$ " do Estado do Ceará, de modo eficiente e correto, a fim de que seja proposto um projeto de implementação para todas as 320 escolas existentes no estado.

\section{Referêncial Teórico}

\section{Norma Técnica $\mathrm{N}^{\circ} 004 / 2008$}

De acordo com a Norma Técnica do Corpo de Bombeiros do Ceará, 2008, existem vários critérios para proteção contra incêndio em edificações e áreas de risco por meio de 
Id on Line Revista Multidisciplinar e de Psicoloqia

Id on Line Multidisciplinary Journal and Psycology

aparelhos extintores de incêndio. Esses critérios se aplicam a todas as edificações com exceção das edificações residenciais unifamiliares.

Para dimensionarmos uma edificação que fique dentro dos padrões exigidos em norma, existem alguns critérios que precisam ser seguidos, dentre eles o tipo de edificação que está sendo empregado, o tipo de extintor que será usado e a capacidade de apagar o fogo.

A Norma Técnica 04, 2008, dimensiona os aparelhos extintores em um ambiente conforme a classificação de risco. A tabela abaixo mostra o dimensionamento dos aparelhos de acordo com a classificação de risco, área e distância a ser percorrida:

Tabela 1 - Distribuição dos Aparelhos Extintores Segundo risco, Área e Distância a ser percorrida

\begin{tabular}{|l|c|c|}
\hline \multicolumn{1}{|c|}{ RISCO } & ÁREA $\left(\mathbf{m}^{2}\right)$ & DISTÂNCIA $(\mathbf{m})$ \\
\hline BAIXO & 500 & 20 \\
\hline MÉDIO & 250 & 15 \\
\hline ALTO & 150 & 10 \\
\hline
\end{tabular}

Fonte: Norma Técnica Do Corpo De Bombeiros Do Ceará, 2008.

Existem vários ambientes em uma escola que podem apresentar variações em sua classificação, podendo ser médio ou baixo risco. O corpo de bombeiro do Estado do Ceará classifica as escolas, de modo geral, como risco médio. Essa constatação se evidência em consideração que as mesmas estão em estado de degradação de sua estrutura física, apresentando umidade e infiltrações que podem gerar um curto circuito, bem como os profissionais não possuem treinamento para circundar um possível incêndio.

Segundo o Corpo de Bombeiros do Estado do Ceará (2008), para classificarmos uma edificação quanto ao risco utilizaremos as normas técnicas NT 001 - Procedimento Administrativo e NT 008 - Carga de incêndio nas edificações e áreas de risco.

Para o correto dimensionamento de uma escola, que fique dentro dos padrões do corpo de bombeiros, todos os itens que são obrigatoriedades na tabela 5E da NT 001/2008 (procedimento administrativo), onde são estabelecidos todos os critérios que devem constar nas edificações do grupo E, que se enquadram as escolas de modo geral devem ser seguidos. 
Id on Line Revista Multidisciplinar e de Psicoloqia

Id on Line Multidisciplinary Journal and Psycology

\section{Área de Risco quanto a Ocupação}

Uma escola dependendo de seu padrão apresenta diversas classificações em relação ao grupo de risco. A escola em estudo possui as seguintes características:

- Dois laboratórios de informática;

- Uma sala de multiméios;

- Núcleo gestor;

- Cantina;

- 4 salas de aulas;

- Um depósito para arquivos.

De acordo com o Corpo de Bombeiro do Estado do Ceará, 2008, para classificarmos uma edificação quanto ao grau de risco temos que levar em consideração o ambiente onde apresenta o maior grau de periculosidade. A edificação em estudo apresenta vários ambientes, mas a norma técnica NT 01, já leva em consideração esses ambientes sendo parte integral da escola. A tabela 01 da NT 01 do Corpo de Bombeiro do Estado do Ceará apresenta vários grupos onde são classificados as edificações. A tabela é dividida da seguinte maneira:

\begin{tabular}{|c|c|c|c|c|}
\hline \multirow{6}{*}{$\mathrm{E}$} & \multirow{6}{*}{$\begin{array}{l}\text { Educacional e } \\
\text { cultura física }\end{array}$} & $\mathrm{E}-1$ & Escola em geral & $\begin{array}{c}\text { Escolas de ensino fundamental e médio, cursos } \\
\text { supletivos, pré-universitários, universitários e } \\
\text { assemelhados. }\end{array}$ \\
\hline & & $\mathrm{E}-2$ & Escola especial & $\begin{array}{c}\text { Escolas de artes e artesanato, escolas religiosas e } \\
\text { assemelhadas. }\end{array}$ \\
\hline & & $\mathrm{E}-3$ & Espaço para cultura física & $\begin{array}{l}\text { Locais de ensino e/ou práticas de artes marciais, } \\
\text { ginástica (artística, dança, musculação e outros) } \\
\text { esportes coletivos (tênis, futebol e outros que não } \\
\text { estejam incluídos em F-3), sauna, casas de } \\
\text { fisioterapia e assemelhados. }\end{array}$ \\
\hline & & E-4 & Centro de treinamento profissional & Escolas profissionais em geral. \\
\hline & & E-5 & Pré-escola & Creches, escolas maternais, jardins-de-infância. \\
\hline & & $\mathrm{E}-6$ & $\begin{array}{c}\text { Escola para portadores de } \\
\text { deficiências }\end{array}$ & $\begin{array}{c}\text { Escolas para excepcionais, deficientes visuais e } \\
\text { auditivos e assemelhados. }\end{array}$ \\
\hline
\end{tabular}

Fonte: Norma Técnica do Corpo de Bombeiro do Estado do Ceará, 2008. 
Achando classificação onde se enquadra a edificação fica fácil saber a carga de incêndio da escola. Na Norma Técnica 01, 2008, existe uma tabela de classificação das edificações e áreas de risco quanto à carga de incêndio, que é a tabela 03. Analisando a tabela quanto a divisão, vemos esse modelo de escola entrar no risco médio, com carga de incêndio entre 300 $\mathrm{MJ} / \mathrm{m}^{2}$ e $1.200 \mathrm{MJ} / \mathrm{m}^{2}$.

Tabela 03 - Classificação das Edificações e Áreas de Risco quanto à Carga de Incêndio.

\begin{tabular}{|c|c|c|c|}
\hline OCUPAÇÃO/USO & DESCRIÇÃO & DIVISÃO & $\begin{array}{c}\text { CARGA DE INCÉNDIO } \\
\left(q_{f i f}\right) \text { EM MJ/m }\end{array}$ \\
\hline \multirow{4}{*}{$\begin{array}{l}\text { Educacionale } \\
\text { Cultura Física }\end{array}$} & Academias de ginástica e similares & $E-3$ & 300 \\
\hline & Pré-escolas e similares & E-5 & 300 \\
\hline & Creches e similares & E-5 & 300 \\
\hline & Escolas em geral & E-1/E2/E4/E6 & 300 \\
\hline
\end{tabular}

Fonte: Norma Técnica do Corpo de Bombeiro do Estado do Ceará, 2008.

\section{Principais Ricos}

O risco de incêndio é caracterizado pela probabilidade do surgimento de um foco de incêndio a partir da interação dos materiais combustíveis tais como papel, móveis de madeira, plásticos objetos estes encontrado com bastante facilidade em uma escola.

Segundo Barreiros, 2006, as causas de incêndios podem ser internas, quando decorrem de fontes internas ao edifício (curto-circuito, fogo em papéis etc.), ou externas, quando são transmitidos por ocorrências exteriores ao edifício, tais como raios, explosões ou por radiação de incêndios próximos. Os principais fatores de causas de incêndios são provocados por instalações elétricas irregulares, atos incendiários e displicência ao cozinhar.

\section{Extintores}

Quanto a importância dos extintores de incêndio para uma edificação, ficou nítido que esta proteção coletiva dentro dos ambientes fará com que a segurança aumente. Entretanto, é necessário oferecer treinamento para o seu uso correto. Outro ponto a ser observado é que os 
extintores devem estar carregados e conferidos, para que estejam adequados quando houver necessidade de seu uso.

A Norma Regulamentadora 23 adotada para classificação de fogo as seguintes nomenclaturas com os respectiva utilidade:

- Classe A - para materiais de fácil combustão com a propriedade de queimarem em sua superfície e profundidade, e que deixam resíduos, como: tecidos, madeira, papel, fibra, etc.;

- Classe B - são considerados os inflamáveis que queimem somente em sua superfície, não deixando resíduos, como óleo, graxas, vernizes, tintas, gasolina, etc.;

- Classe C - para equipamentos elétricos energizados como motores, transformadores, quadros de distribuição, fios, etc.

- Classe D - para elementos pirofóricos como magnésio, zircônio, titânio.

No mercado, também existem os extintores que podem combater mais de uma classe de incêndio, que são os extintores $\mathrm{BC}$ e $\mathrm{ABC}$. Para facilitar o uso e manuseio o Corpo de Bombeiros do Ceará permite a instalação de duas unidades aparelho extintoras iguais de pó $\mathrm{ABC}$ em uma edificação.

\section{Metodologia}

Este trabalho é um estudo de campo, de natureza exploratória. no município de Russas, na rua Lima Ramalho. O projeto teve início em junho de 2015, estendendo-se até novembro de 2015 .

\section{Resultados e Discussões}

A escola foi classificada como risco médio. Assim, cada extintor tem que abranger uma área de $250 \mathrm{~m}^{2}$ e distar do ponto mais longe 15 metros. A norma permite trocarmos extintores A, B e C por extintores $\mathrm{ABC}$. Nesse trabalho será dimensionado em todos os ambientes 
extintores ABC. Assim, dividirei a escola em 3 partes para facilitar a explicação do dimensionamento:

1. Áreas Comuns: Pátios, corredores, quadras e estacionamentos (utilizados tanto por professores, como por alunos, funcionários, visitantes e fornecedores);

2. Áreas mistas: Salas de aula e outros ambientes didáticos como laboratórios e bibliotecas (utilizados exclusivamente por professores e alunos);

3. Áreas de uso exclusivo: Sala dos professores, cozinha, almoxarifado e depósitos (utilizados exclusivamente por funcionários).

\section{Áreas Comuns}

Essas áreas não possuem uma carga de incêndio grande mas, podem estão expostas a riscos de incêndio devido ao grande fluxo de pessoas que transitam nesses ambientes. Os principais ricos de incêndio encontrados nesses locais são:

- Falta de limpeza e acúmulo de lixo capazes de gerar uma combustão;

- Falhas e descuidos em consertos e manutenções, principalmente quando se usam materiais como soldas, maçaricos, tintas e outros produtos ou materiais capazes de dar início a um incêndio;

- Depositar nos ambientes materiais com grandes cargas de combustão como papéis, plásticos e madeira utilizados em decorações de eventos, festas e gincanas;

- Raios e outros fenômenos naturais e atmosféricos;

- Incêndio criminoso ou atos de sabotagem ou terrorismo.

A imagem I mostra o pátio da escola onde comumente são fixados bandeiras, cartazes, cestos de lixo e decorações comemorativas da escola. Os extintores estão a menos de 15 metros do ponto mais longe a percorrer, estando assim dentro das normas do corpo de bombeiros. A escola não possui estacionamento e nem quadra, ficando assim sem dimensionamento. 
IMAGEM I- Pátio da escola

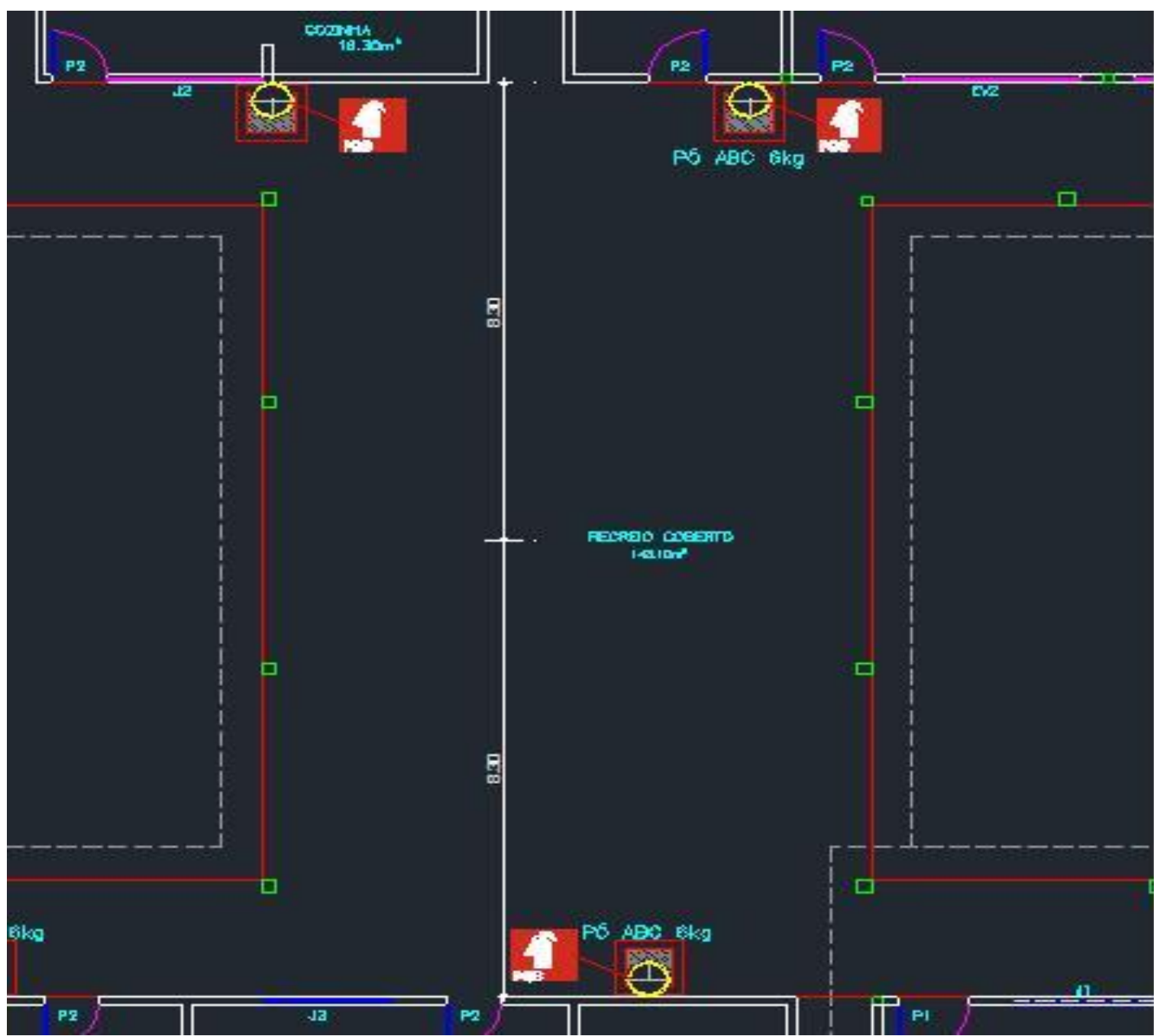

\section{Áreas Mistas}

São áreas onde os integrantes da escola passam a maior parte do tempo, nessas áreas os principais ricos de incêndio são causados por:

- Abuso ou negligência no uso de aparelhos elétricos ou eletrônicos no local, principalmente, em relação ao tempo que ficam ligados ou quando existe incompatibilidade de voltagem entre eles e o sistema elétrico da escola;

- Uso de materiais de fácil combustão, em aulas ou exercícios, como produtos químicos, plásticos, madeira e papel; 
- Incêndio criminoso ou atos de sabotagem ou terrorismo.

A imagem II mostra as salas de aulas onde os extintores estão localizados na parte externa das salas. A questão da não colocação do aparelho extintor dentro das salas de aulas é devido a estética e a não obrigatoriedade da norma de instalar dentro das salas.

IMAGEM II: Salas de aulas

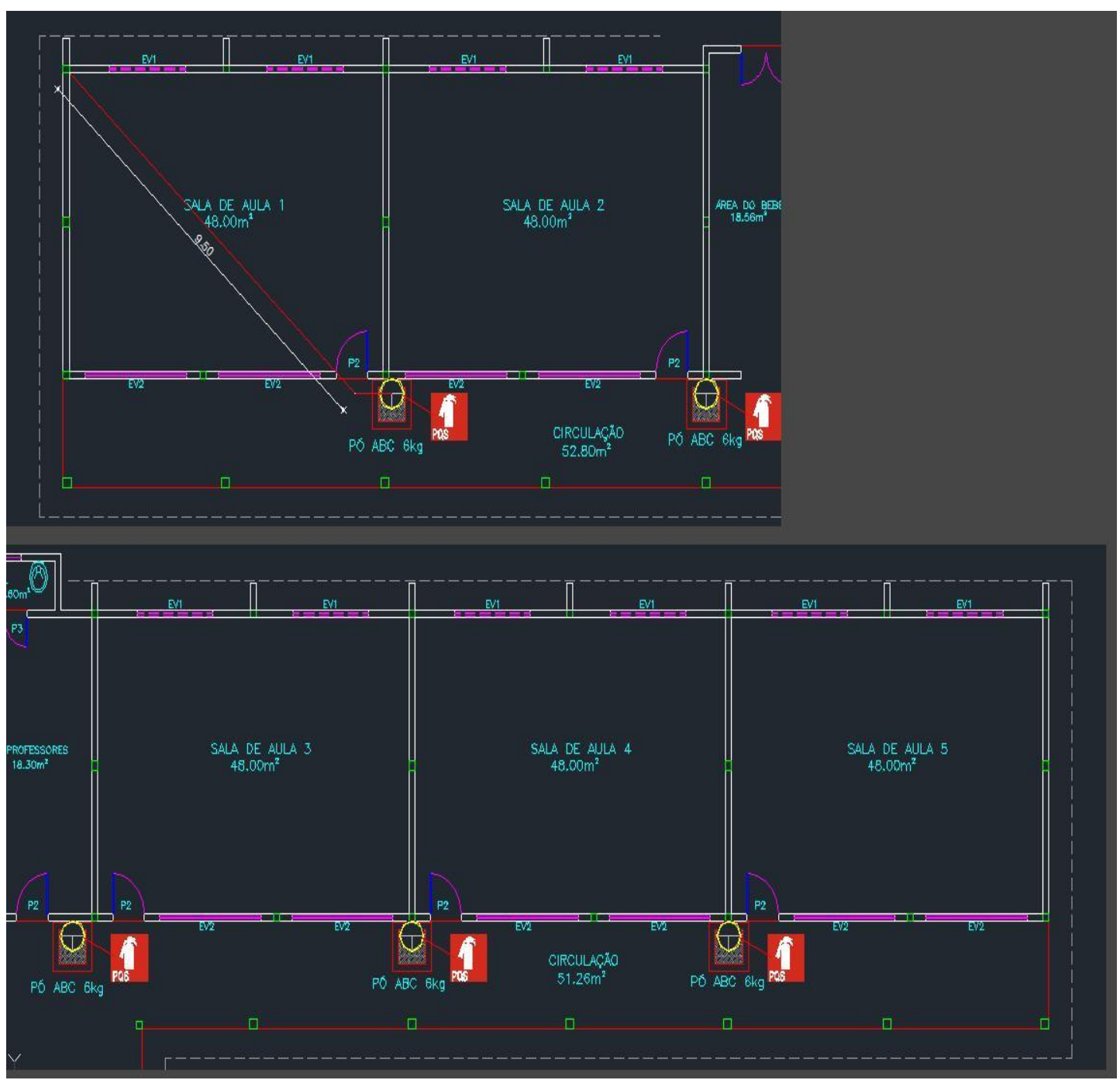

A imagem III mostra a sala de multimeios e o laboratório de ciências. A necessidade de colocar extintores dentro ou fora do ambiente, nesse caso, depende do projetista. Em relação a sala de multimeios como é um ambiente onde se concentra uma enorme quantidade de livros e uma grade quantidade de tomadas e equipamentos elétricos ligados, há um extintor de classe 
$\mathrm{ABC}$ dentro do ambiente, pois em casos de princípios de incêndio seja apagado o mais rápido possível. O laboratório de ciência está dimensionado um extintor para parte externa da sala, porque além de não possuírem uma grande quantidade de materiais de fácil combustão a manipulação desses materiais sempre é inspecionado de perto por professores experientes.

IMAGEM III: Sala de Multiméios e Laboratórios

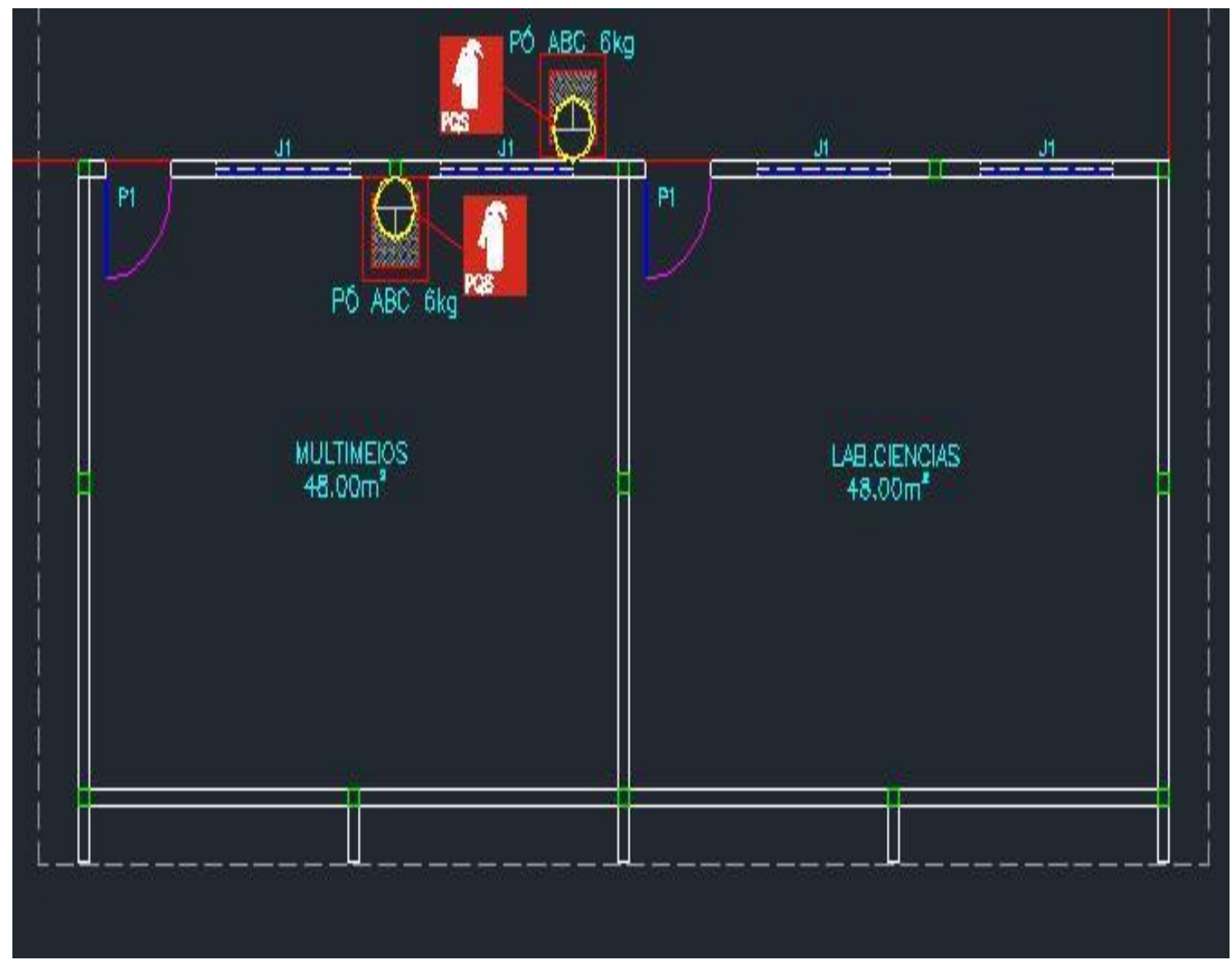

\section{Áreas de uso exclusivo}

São áreas usadas apenas por funcionários da escola, os principais ricos de incêndio são causados por:

- Falhas e acidentes elétricos, principalmente, curtos-circuitos e sobrecarga em equipamentos como motores, aquecedores, iluminação e transformadores, entre outros; 
- Grande quantidade de produtos inflamáveis em locais onde não haja segurança, principalmente, durante reformas e pinturas.

A imagem 04 mostra o núcleo gestor onde existem 2 extintores, um localizado na parte interna do ambiente e outro na parte externa. A instalação do aparelho extintor no interior do ambiente foi devido à grande quantidade de papéis presente nesse ambiente e ao grande número de aparelhos ligados. O aparelho extintor localizado na parte externa cobre tanto a secretaria como parte do pátio e o hall da entrada.

\section{IMAGEM IV: Núcleo Gestor.}

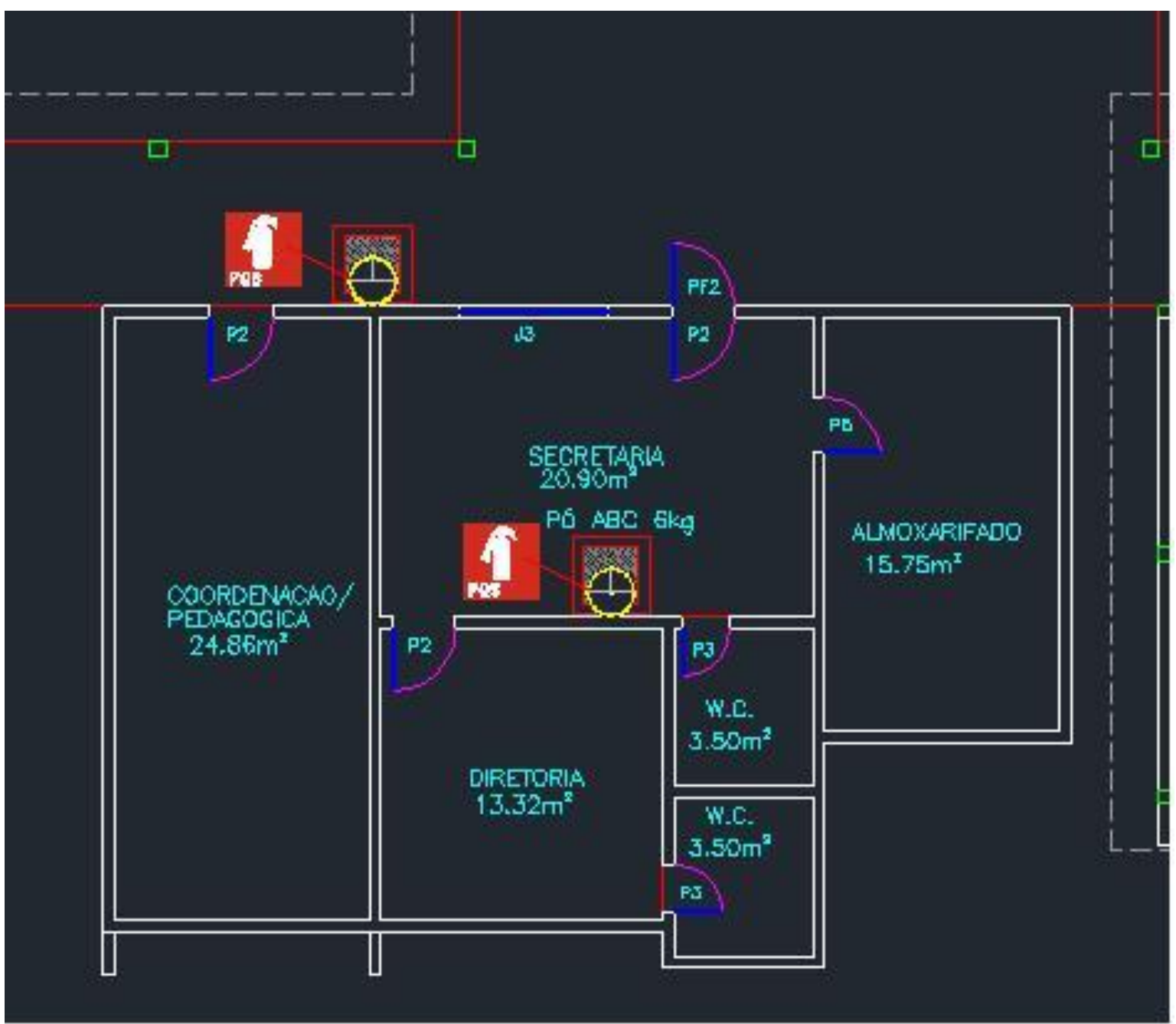


Id on Line Revista Multidisciplinar e de Psicoloqia

Id on Line Multidisciplinary Journal and Psycology

\section{Modo de instalação, manutenção e sinalização}

Os extintores deverão ser fixados a 1,60 m do piso, como mostra imagem 05 , sempre em alvenaria ou quando a parede for de gesso acartonado, deve-se instalar na parede um perfil de aço galvanizado para reforço interno. Sua instalação deverá ficar posicionado de modo que caso haja um princípio de incêndio o fogo não bloqueia seu acesso. Eles devem sempre estar desobstruídos e devidamente sinalizado com boa visibilidade. Devem possuir no mínimo $1 \mathrm{~m}^{2}$ de área livre, pintado na cor vermelha com faixa na cor amarela. Caso a escola escolha optar em instalar extintores sobre rodas eles deve seguir o item 4.2.2 da NT 004/2008 (aparelhos extintores sobre rodas) do Corpo de Bombeiro do Estado do Ceará.

A manutenção nos aparelhos extintores não passa da uma verificação do prazo de validade de cada unidade e da análise periódica da pressão que se encontra em cada extintor. Muitos ainda hoje não sabe da importância que tem um aparelho extintor dentro de uma unidade comercial e tende a brincar secando. Por isso, deve ser inspecionado nas escolas semanalmente cada aparelho extintor.

IMAGEM V: Detalhe do extintor fixado na parede

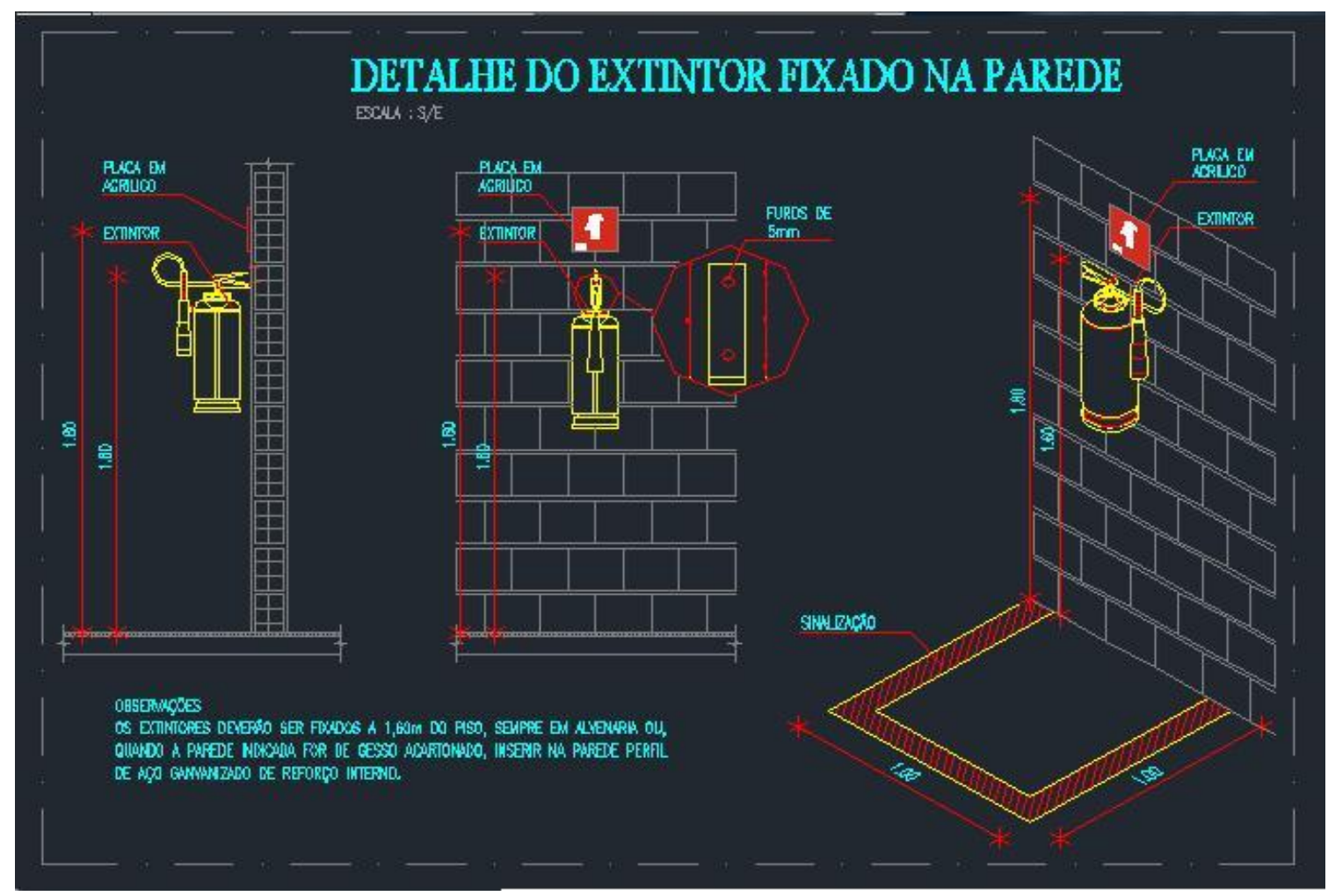


Id on Line Revista Multidisciplinar e de Psicoloqia

Id on Line Multidisciplinary Journal and Psycology

A norma que rege a sinalização de incêndio é a NBR 13.434 (Sinalização de segurança contra incêndio e pânico).

IMAGEM IV: Detalhe da placa

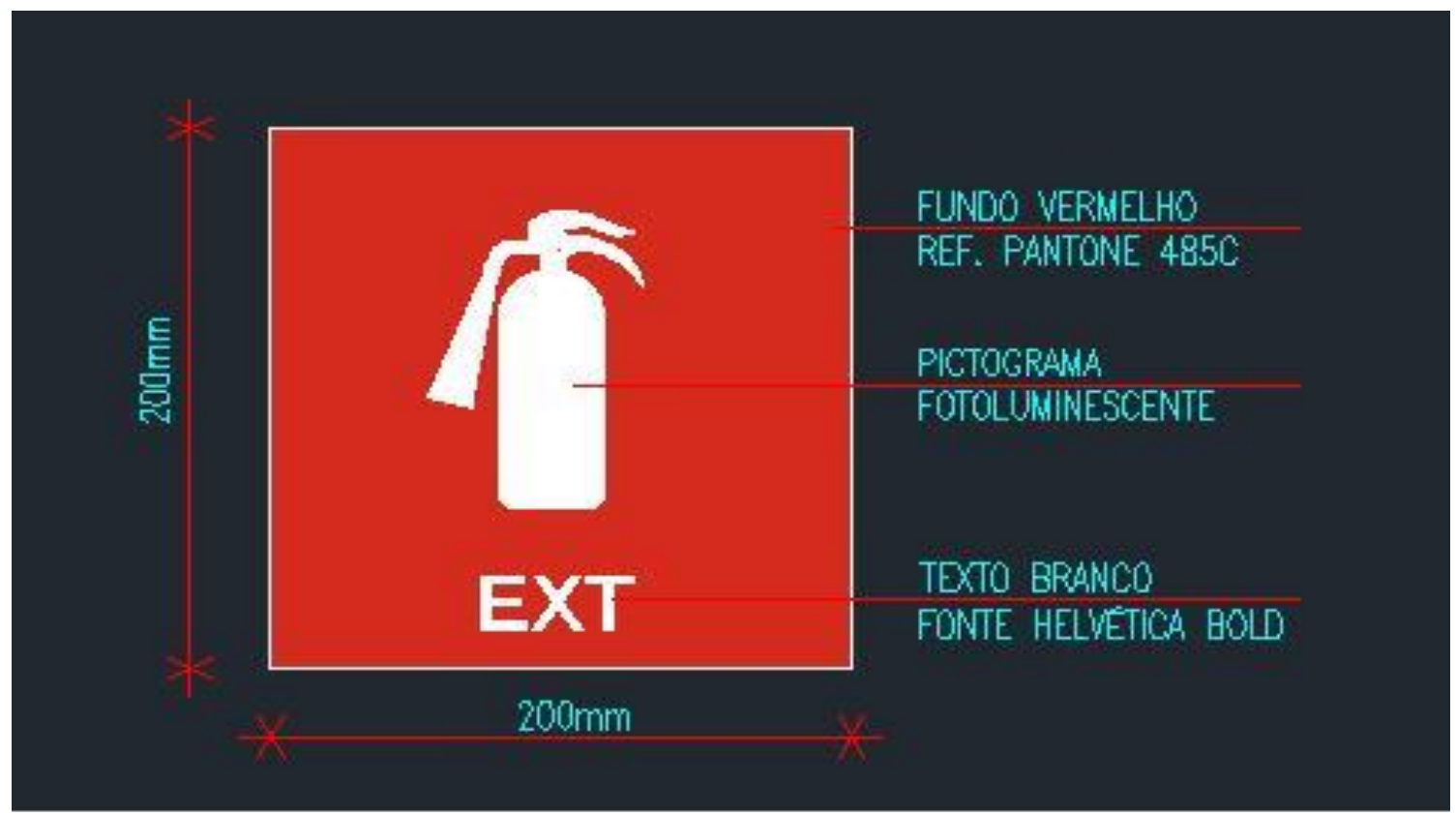

Essa norma regulamenta tanto a altura como as cores de cada placa. A imagem 06 detalha as especificações técnicas da placa que indica a existência dos extintores.

\section{Conclusão}

Nos últimos anos o ministério da educação está autuando as escolas que não apresentarem um sistema de proteção contra incêndio e pânico. Como a maiorias das escolas do estados do Ceará são edificações antigas da década de 70 a 90 há uma grande dificuldade de projetar um sistema eficaz que combate a fogo nessas escolas.

O presente estudo, na busca de alcançar um coreto dimensionamento dos aparelhos extintores, elaborou um projeto para uma escola antiga, dimensionando os aparelhos extintores onde possa ser mais eficaz seu uso. Algumas observações devem ser feitas ao se utilizarem esses aparelhos. Periodicamente deve ser inspecionado esses equipamentos de modo a evitar que possíveis alunos sequem sem os gestores verem, os prazos de validades 
também devem ser checados, pois os fabricantes so garantem o funcionamento quando o equipamento esteja dentro do prazo de validade.

Este trabalho não pretende esgotar o tema tratado pelo estudo, mas contribuir para novos estudos e pesquisas numa área ainda tão carente desse tipo de trabalho.

\section{Referências}

NBR 9443 - Extintor de incêndio classe A - Ensaio de fogo em engradado de madeira NBR 9444 - Extintor de incêndio classe B - Ensaio de fogo em líquido inflamável NBR 10721 - Extintores de incêndio com carga de pó NBR11716 - Extintores de incêndio com carga de dióxido de carbono (gás carbônico) NBR 11751 - Extintores de incêndio com carga para espuma mecânica NBR 12962 - Inspeção, manutenção e recarga em extintores de incêndio NBR 12992 - Extintores de incêndio classe C - Ensaio de condutividade Elétrica NBR 14100 - Proteção contra incêndio - Símbolos gráficos para Projetos Barreiros - revistas.unoeste.br/revistas/ojs/index.php/ce/article/viewFile/401/826 Corpo de Bombeiros do Estado do Ceará, normas técnicas. 2008

\section{Como citar este artigo (Formato ABNT):}

CARVALHO, K.V.R.; FALCÃO, B.L. Métodos de sistemas de proteção por extintores. Id on Line Revista Multidisciplinar e de Psicologia, Set-Out de 2016, vol.10, n.31, Supl 2, p. 100-113. ISSN 1981-1179.

Recebido: 15/09/2016

Aceito: 22/09/2016 